\title{
Mean Value of Median Nerve Cross-sectional Area in Healthy 20s and 30s in Busan Area
}

\author{
Kyoung-Hwa Kang ${ }^{1, *}$, Gil-Hyun Lee ${ }^{2, *}$, Go-Eun Choi ${ }^{3, *}$ and Kyung-Yae Hyun ${ }^{2, ;, *}$ \\ ${ }^{1}$ Department of Neurology, Pusan National University, Yangsan Hospital, Yangsan 50612, Korea \\ ${ }^{2}$ Department of Clinical Laboratory Science, Dong-Eui University, Busan 47340, Korea \\ ${ }^{3}$ Department of Clinical Laboratory Science, Catholic University of Pusan, Busan 46252, Korea
}

This study was designed to investigate the median nerve cross-sectional area of the upper extremity which is the main cause of CTS in the 20s and 30s. The median nerve cross-sectional area (MNC-area) of each part of the upper limb was measured in healthy 20s and 30s females and males without neurological diseases or other diseases. This MNC-area was compared with the hand, wrist, finger, and other body indexes. The research group was divided into 20 s female and male groups, and the 30s were also divided into female and male groups. In the comparison between the ages, the hand, and wrist configurations in the $30 \mathrm{~s}$ were significantly higher than those of the $20 \mathrm{~s}$. The mean median nerve cross-sectional area was significantly larger in the male group than in the female group in both $20 \mathrm{~s}$ and $30 \mathrm{~s}$, and it was larger in both men and women than in the 20s. Hand and wrist configurations were also positively correlated with the median nerve cross-sectional area in both $20 \mathrm{~s}$ and $30 \mathrm{~s}$. The median values of hand ratio and wrist ratio were 2.26 and 0.65 , respectively. This median value of hand ratio was inversely correlated with the median nerve cross-sectional area. The median nerve cross-area of the 20s was $6.88 \sim 7.38 \mathrm{~mm}^{2}$ in the male group and $5.69 \sim 6.99 \mathrm{~mm}^{2}$ in the female group, respectively. The median nerve cross-area of the $30 \mathrm{~s}$ was $6.32 \sim 8.89 \mathrm{~mm}^{2}$ in the male group and $6.15 \sim 7.17 \mathrm{~mm}^{2}$ in the female group, respectively. The mean median nerve cross-sectional area was positively correlated with body mass index in both groups. Most of the variables were higher in their 30s than in their 20s.

Key Words: Twenties, Thirties, Median nerve cross sectional area, Hand and wrist configuration

\section{INTRODUCTION}

The carpal tunnel is a small passageway formed by the bones and ligaments of the wrist beneath the skin tissue in front of the wrist, where nine tendons and one median nerve pass through the hand. It causes numbness, pain, and hypomotility on the palms and fingers (Katz et al., 1982). Patients who do not understand the pathologic severity of the disease are often forced to go to the hospital only after their muscular atrophy has progressed considerably. Although the precise mechanism of carpal tunnel syndrome has not been elucidated, it is theoretically possible to cause any case that can reduce the cross-section of the carpal tunnel, but in most cases, it is the most common cause of the pressure on the nerve by thickening the ligament covering the carpal tunnel. Housewives who spend their days working on domestic labor, those who work with knocking on a computer key-

Received: July 6, 2020 / Accepted: September 1, 2020

* Professor.

${ }^{\dagger}$ Corresponding author: Kyung-Yae Hyun. Department of Clinical Laboratory Science, Dong-Eui University, Busan 47340, Korea. Tel: +82-51-890-2683, Fax:+82-0505-182-6877, e-mail: kyhyun@deu.ac.kr

(C) The Korean Society for Biomedical Laboratory Sciences. All rights reserved.

(C) This is an Open Access article distributed under the terms of the Creative Commons Attribution Non-Commercial License (http://creativecommons.org/licenses/by-nc/3.0/) which permits unrestricted non-commercial use, distribution, and reproduction in any medium, provided the original work is properly cited. 
board, or those who spend a lot of computer games or cell phone letters can get sick. The average annual growth rate was $10.7 \%$. In terms of medical expenses, it increased by about 120 billion (59.4\%) over five years from 200 billion in 2007 to 320.2 billion in 2011, and the average annual growth rate was $12.4 \%$. Carpal tunnel syndrome (CTS) shows symptoms such as pain, numbness and burning sensation in the hand, sensory impairment of the median nerve distribution site, and atrophic muscle atrophy. Additionally, pain is accompanied by an abnormally delayed neurotransmission rate to confirm the extent of the precise site can not find the disadvantage. Recently, diagnostic tests using ultrasonography have been gradually expanded. Therefore, it is possible to find the precise location of the disease and to distinguish it easily from other neuromuscular diseases. Kutlar et al. Recently reported that Doppler ultrasonography is a very useful diagnostic test for determining the severity of CTS (Kutlar et al., 2017). The guideline for the diagnosis of CTS through ultrasonography has been using the normal value of the median nerve cross-sectional area (CSA), which has been widely used worldwide. However, applying the CSA normal value of the median nerve to the Korean population may be inappropriate. Therefore, in this study, we will present a guideline for them by analyzing the normal value of median nerve CSA adaptable to Koreans. For the purpose of this study, we studied healthy adults in their 20 s and 30 s who are well-suited for CTS.

\section{MATERIALS AND METHODS}

\section{Subjects}

A study was conducted on 200 healthy volunteers who did not have carpal tunnel syndrome (CTS) in their 20s and 30s (HI-Ob scale) (Table 1). The subjects of this study were believers in the 'A' catholic church in Busan. In this study, the criteria to be excluded were carpal tunnel syndrome and musculoskeletal disease patients, those who had experienced one or two specific surgery, diabetes patients, hypertension patients, cancer patients, arthritis patients, rheumatic disease patients, autoimmune disease patients, neurological patients. This study was supported by the Institutional Review Board (IRB) Catholic University of Pusan.

\section{Body measurements}

The weight and height were measured, and we check whether the handle is right or left handed. Then the hand ratio [(palm length + third digit length) / palm width] and the wrist ratio (wrist depth / wrist width) were also measured.

\section{Measurement of cross sectional area size by neuro- ultrasound}

Ultrasonography was used to measure the cross sectional area size (CSA) of median nerve angular position (wrist, midforearm, and mid-arm. The equipment used in this experiment was PROSOUND ALPHA7 (Hitachi Aloka Medical, Ltd., Japan).

\section{RESULTS}

\section{Wrist condition of subjects}

Participants who were finally selected in this study were both normal in Phalen's test and Tinel's pain

\section{The evaluation of the nerve conduction study}

All participants in the nerve conduction study had no capal tunnel syndrome (CTS).

\section{The basic data of the participants}

Among the total number of patients, the twenties were 240 (140 females vs. 100 males) and the thirties were 216 (112 females vs. 104 males)

All subjects had no any diseases and the remaining data are shown in Table 1.

\section{The hand and wrist configurations in the subjects}

Table 2 shows the hand and wrist configurations of the subjects. In the twenties (20s), the male group had larger variables than the female group $(P<0.05)$. In the thirties (30s), the male group was also higher than the female group In all age groups, all of the variables were larger than those in the $20 \mathrm{~s}(P<0.05)$. In the comparison between age groups, most of the variables were larger in the $30 \mathrm{~s}$ than in the $20 \mathrm{~s}$ $(P<0.05)$ (Table 2) 
Table 1. The basic data in twenties and thirties

\begin{tabular}{lccccc}
\hline \hline \multirow{2}{*}{ Variable } & \multicolumn{2}{c}{ Twenties $(\mathrm{n}=240)$} & & \multicolumn{2}{c}{ Thirties $(\mathrm{n}=216)$} \\
\cline { 2 - 3 } \cline { 5 - 6 } & $\mathrm{F}$ & 100 & $\mathrm{~F}$ & 112 & $\mathrm{M}$ \\
\hline Sample size (no.) & 140 & $23.21 \pm 3.02$ & & $33.12 \pm 2.24$ & $34.03 \pm 3.16$ \\
Age (year) & $23.09 \pm 2.57$ & $173.55 \pm 5.11^{*}$ & & $162.14 \pm 4.32$ & $174.20 \pm 3.50^{*}$ \\
Height $(\mathrm{cm})$ & $161.03 \pm 5.62$ & $70.45 \pm 10.68^{*}$ & & $58.72 \pm 10.26$ & $72.75 \pm 9.67^{*}$ \\
Weight $(\mathrm{kg})$ & $57.40 \pm 10.57$ & $23.21 \pm 3.01^{*}$ & & $21.27 \pm 3.52$ & $23.95 \pm 2.64^{*}$ \\
BMI $\left(\mathrm{m}^{2}\right)$ & $22.09 \pm 3.56$ & None & & None & None \\
Nerve disease & None & & & \\
\hline
\end{tabular}

Data are expressed mean \pm standard deviation (SD)

$*, P<0.05$ (statistical significance compared with the female group)

Abbreviation: F, female; M, male; BMI, body mass index

Table 2. Comparison of the hand and wrist configurations between the twenties and thirties

\begin{tabular}{|c|c|c|c|c|}
\hline \multirow{2}{*}{ Part of hand } & \multicolumn{2}{|c|}{ Twenties $(n=240)$} & \multicolumn{2}{|c|}{ Thirties $(n=216)$} \\
\hline & $\mathrm{F}$ & M & $\mathrm{F}$ & M \\
\hline Palm portrait-R $(\mathrm{cm})$ & $9.75 \pm 0.51$ & $10.57 \pm 0.70^{* \dagger}$ & $9.84 \pm 0.53^{\dagger}$ & $10.47 \pm 0.48^{*}$ \\
\hline Palm portrait-L $(\mathrm{cm})$ & $9.63 \pm 0.58$ & $10.63 \pm 0.64^{* \dagger}$ & $9.85 \pm 0.47^{\dagger}$ & $10.47 \pm 0.31^{*}$ \\
\hline Palm horizontal-R $(\mathrm{cm})$ & $7.58 \pm 0.38$ & $8.33 \pm 0.59^{*}$ & $7.72 \pm 0.53^{\dagger}$ & $8.61 \pm 0.37^{* \dagger}$ \\
\hline Palm horizontal-L $(\mathrm{cm})$ & $7.49 \pm 0.53$ & $8.24 \pm 0.55^{*}$ & $8.76 \pm 0.37^{\dagger}$ & $8.45 \pm 0.36^{\dagger}$ \\
\hline Third finger-R $(\mathrm{cm})$ & $7.34 \pm 0.53$ & $7.81 \pm 0.46^{*}$ & $7.48 \pm 0.48^{\dagger}$ & $7.79 \pm 0.36^{*}$ \\
\hline Third finger-L (cm) & $7.37 \pm 0.56$ & $7.82 \pm 0.46^{*}$ & $7.84 \pm 0.29^{\dagger}$ & $7.86 \pm 0.35$ \\
\hline Wrist horizontal-R $(\mathrm{cm})$ & $4.02 \pm 2.67$ & $5.14 \pm 1.27^{*}$ & $4.92 \pm 0.52^{\dagger}$ & $5.76 \pm 0.60^{* \dagger}$ \\
\hline Wrist horizontal-L (cm) & $4.03 \pm 1.74$ & $5.09 \pm 1.25^{*}$ & $4.78 \pm 0.43^{\dagger}$ & $5.75 \pm 0.50^{* \dagger}$ \\
\hline Wrist depth-R (cm) & $2.92 \pm 1.74$ & $3.29 \pm 0.94^{*}$ & $3.58 \pm 0.23^{\dagger}$ & $4.45 \pm 0.50^{* \dagger}$ \\
\hline Wrist depth-L (cm) & $2.69 \pm 1.75$ & $3.31 \pm 0.95^{*}$ & $3.59 \pm 0.23^{\dagger}$ & $4.36 \pm 0.57^{* \dagger}$ \\
\hline
\end{tabular}

Data are expressed mean \pm SD

$*, P<0.05$ (statistical significance compared with the female group); $\uparrow, P<0.05$ (statistical significance compared with the twenties) Abbreviation: F, female; M, male; R, right; L, left

Table 3. Comparison of the hand ratio between twenties and thirties

\begin{tabular}{cccccc}
\hline \hline \multirow{2}{*}{ Ratio } & \multicolumn{2}{c}{ Twenties $(\mathrm{n}=240)$} & & \multicolumn{2}{c}{ Thirties $(\mathrm{n}=216)$} \\
\cline { 2 - 3 } \cline { 5 - 6 } & $\mathrm{F}$ & $\mathrm{M}$ & & $\mathrm{F}$ & $\mathrm{M}$ \\
\hline Hand ratio-R & $2.23 \pm 0.12$ & $2.21 \pm 0.12$ & & $2.30 \pm 0.11$ & $2.13 \pm 0.09^{*}$ \\
Hand ratio-L & $2.28 \pm 0.11$ & $2.24 \pm 0.13$ & & $2.48 \pm 1.27$ & $2.17 \pm 0.13^{*}$ \\
Wrist ratio-R & $0.66 \pm 0.04$ & $0.68 \pm 0.04$ & & $0.68 \pm 0.03$ & $0.79 \pm 0.19^{* \dagger}$ \\
Wrist ratio-L & $0.68 \pm 0.04$ & $0.69 \pm 0.05$ & & $0.68 \pm 0.04$ & $0.75 \pm 0.25^{* \dagger}$ \\
\hline
\end{tabular}

Data are expressed mean \pm SD

*, $P<0.05$ (statistical significance compared with the female group); $\uparrow, P<0.05$ (statistical significance compared with the twenties) Abbreviation: F, female; M, male; R, right; L, left

\section{The hand ratio in the subjects}

In the $30 \mathrm{~s}$, the hand ratio- $\mathrm{R}$ and hand ratio-L of the male group were significantly lower than those of the female group $(P<0.05)$ (Table 3). However, the wrist ratio-R and wright ratio-L levels of the 30s-male group were significantly 
Table 4. Comparison of the median nerve-CSA between twenties and thirties

\begin{tabular}{|c|c|c|c|c|}
\hline \multirow{2}{*}{ Location of $\mathrm{MN}$} & \multicolumn{2}{|c|}{ Twenties $(n=240)$} & \multicolumn{2}{|c|}{ Thirties $(n=216)$} \\
\hline & $\mathrm{F}$ & M & $\mathrm{F}$ & M \\
\hline Wrist crease- $\mathrm{R}\left(\mathrm{mm}^{2}\right)$ & $6.99 \pm 1.83$ & $7.29 \pm 1.50^{*}$ & $7.17 \pm 1.06^{\dagger}$ & $8.89 \pm 1.23^{* \dagger}$ \\
\hline Wrist crease-L $\left(\mathrm{mm}^{2}\right)$ & $6.77 \pm 1.35$ & $7.38 \pm 1.39^{*}$ & $7.12 \pm 1.10^{\dagger}$ & $8.05 \pm 1.18^{* \dagger}$ \\
\hline Mid-foream-R ( $\left.\mathrm{mm}^{2}\right)$ & $5.69 \pm 1.11$ & $6.79 \pm 1.56^{*}$ & $6.35 \pm 1.20^{\dagger}$ & $6.89 \pm 1.26^{* \dagger}$ \\
\hline Mid-foream-L (mm²) & $5.69 \pm 1.10$ & $6.79 \pm 1.44^{*}$ & $6.33 \pm 1.21^{\dagger}$ & $7.21 \pm 1.20^{*}$ \\
\hline Mid-arm-R (mm²) & $6.00 \pm 1.21$ & $6.89 \pm 1.20^{*}$ & $6.15 \pm 1.12^{\dagger}$ & $6.58 \pm 1.17^{*}$ \\
\hline Mid-arm-L (mm²) & $5.99 \pm 1.12$ & $6.88 \pm 1.25^{*}$ & $6.31 \pm 1.23^{\dagger}$ & $6.32 \pm 1.20$ \\
\hline Axilla- $\mathrm{R}\left(\mathrm{mm}^{2}\right)$ & $6.40 \pm 1.06$ & $7.26 \pm 1.47^{*}$ & $6.67 \pm 1.23^{\dagger}$ & $7.58 \pm 1.07^{* \dagger}$ \\
\hline Axilla-L $\left(\mathrm{mm}^{2}\right)$ & $6.54 \pm 1.10$ & $7.04 \pm 1.21^{*}$ & $6.71 \pm 1.18^{\dagger}$ & $7.26 \pm 1.17^{* \dagger}$ \\
\hline Swelling ratio- $\mathrm{R}\left(\mathrm{mm}^{2}\right)$ & $1.24 \pm 0.30$ & $1.09 \pm 0.22^{*}$ & $1.15 \pm 0.24$ & $1.30 \pm 0.20^{* \dagger}$ \\
\hline Swelling ratio-L $\left(\mathrm{mm}^{2}\right)$ & $1.21 \pm 0.27$ & $1.10 \pm 0.24^{*}$ & $1.20 \pm 0.26$ & $1.12 \pm 0.21^{*}$ \\
\hline
\end{tabular}

Data are expressed mean $\pm \mathrm{SD}$

*, $P<0.05$ (statistical significance compared with the female group); $\uparrow, P<0.05$ (statistical significance compared with the twenties) Abbreviation: CSA, cross sectional areas; $\mathrm{MN}$, median nerve; $\mathrm{F}$, female; $\mathrm{M}$, male; $\mathrm{R}$, right; $\mathrm{L}$, left

Table 5. Comparison of the size of the median nerve-CSA according to the hand ratio and wrist ratio in the subjects

\begin{tabular}{|c|c|c|c|c|}
\hline \multirow{2}{*}{ Location of MN } & \multicolumn{2}{|c|}{ Hand ratio } & \multicolumn{2}{|c|}{ Wrist ratio } \\
\hline & $<2.26$ & $\geq 2.26$ & $<0.65$ & $\geq 0.65$ \\
\hline Wrist crease- $\mathrm{R}\left(\mathrm{mm}^{2}\right)$ & $7.67 \pm 2.05$ & $6.65 \pm 1.29^{*}$ & $7.03 \pm 1.24$ & $7.35 \pm 2.02^{*}$ \\
\hline Wrist crease-L $\left(\mathrm{mm}^{2}\right)$ & $7.46 \pm 1.66$ & $7.01 \pm 1.40^{*}$ & $7.09 \pm 1.28$ & $7.33 \pm 1.66^{*}$ \\
\hline Mid-foream-R (mm²) & $6.26 \pm 1.42$ & $5.98 \pm 1.07^{*}$ & $5.78 \pm 1.13$ & $6.29 \pm 1.14^{*}$ \\
\hline Mid-foream-L (mm²) & $6.36 \pm 1.44$ & $5.94 \pm 0.07^{*}$ & $5.86 \pm 1.01$ & $6.31 \pm 1.27^{*}$ \\
\hline Mid-arm-R (mm²) & $6.45 \pm 1.28$ & $5.94 \pm 1.19^{*}$ & $6.40 \pm 1.15$ & $6.19 \pm 1.31^{*}$ \\
\hline Mid-arm-L $\left(\mathrm{mm}^{2}\right)$ & $6.36 \pm 1.28$ & $6.12 \pm 1.09^{*}$ & $6.32 \pm 1.33$ & $6.25 \pm 1.17^{*}$ \\
\hline Axilla-R (mm²) & $6.80 \pm 1.30$ & $6.53 \pm 1.14^{*}$ & $6.66 \pm 1.06$ & $6.70 \pm 1.31^{*}$ \\
\hline Axilla-L (mm²) & $6.94 \pm 1.29$ & $6.53 \pm 0.95^{*}$ & $6.62 \pm 1.00$ & $6.83 \pm 1.24^{*}$ \\
\hline Swelling ratio- $\mathrm{R}\left(\mathrm{mm}^{2}\right)$ & $1.24 \pm 0.27$ & $1.13 \pm 0.21^{*}$ & $1.05 \pm 0.27$ & $1.18 \pm 0.25^{*}$ \\
\hline Swelling ratio-L $\left(\mathrm{mm}^{2}\right)$ & $1.20 \pm 0.20$ & $1.16 \pm 0.25^{*}$ & $1.17 \pm 0.26$ & $1.19 \pm 0.5^{*}$ \\
\hline
\end{tabular}

Data are expressed mean $\pm \mathrm{SD}$

*, $P<0.05$ (statistical significance compared with hand ratio $<2.26$ or wrist ratio $<0.65$ )

Abbreviation: R, right; L, left

higher than those of the female group as well as those of the 20s-male and female groups $(P<0.05)$ (Table 3$)$.

\section{The size of the median nerve-CSA in the subjects}

The size of the median nerve-CSA was significantly larger in the male group than in the female group in both 20 s and 30s $(P<0.05)$. In the comparision between age, all the 30s-male and female-groups were significantly larger than the 20s-male and female groups $(P<0.05)$ (Table 4).
The size of the median nerve-CSA according to the median values of hand and wrist ratios in the subjects

Table 5 shows the differences in the size of the median nerve-CSA according to the median values of the hand and wrist ratios. The median value of hand ratio was 2.26 and the median wrist ratio was 0.65 in the subjects, so the size of the median nerve cross-sectional area was compared based on the median values of these two parameters. The subjects 
with the $\geq 2.26$ and $\geq 0.65$ had higher size of the median nerve-CSA $(P<0.05)$.

\section{DISCUSSION}

Carpal tunnel syndrome (CTS) is the most common peripheral nerve entrapment syndrome. It is caused by the pressure in the carpal tunnel being elevated and the median nerve is compressed. The numbness or sensory abnormality occurs in the thumb, 2nd, and 3rd fingers, which are the sensory areas dominated by the median nerve, and the weakness of the thumb muscle in the atrophy of the thymus (the thumb) is the main symptom of the disease (Rempel et al., 1998; Bongers et al., 2007; Palmer et al., 2007).

In the present study, the hand and wrist configurations and the median nerve cross-sectional area of the $20 \mathrm{~s}$ and 30 s male groups were significantly larger than those of the 20 s and 30 s female and male groups, respectively. In the comparison between the age groups, the values of these parameters were higher in the 30 s than in the 20 s.

Only the cross-sectional area of the carpal tunnel and even wrist dimensions have been reported to be important factors in the development of idiopathic CTS (Stallings et al., 1997).

However, the results of the relatively high levels of these variables in the 20th and 30th male groups of this study are more likely to be due to normal anatomical differences between men and women.

On the other hand, (Burg et al., 2014) found interesting results in a study comparing median nerve cross-sectional areas between Indians and Dutch. The mean median nerve cross-sectional area in this study was $6.34 \mathrm{~mm}^{2}$ and $7.13 \mathrm{~mm}^{2}$, respectively for the female and male groups in the $20 \mathrm{~s}$, and $6.66 \mathrm{~mm}^{2}$ and $7.61 \mathrm{~mm}^{2}$ in the female and male groups in the $30 \mathrm{~s}$, respectively. In this study, the mean median nerve cross-sectional areas of men were similar to those of the Indian group, which is considered in the diagnosis of agerelated CTS, because the median nerve cross-sectional area of Asian ethnicity is smaller than that of European ethnicity.

Recently, studied the median nerve cross-sectional area of 80 Korean (40 males vs. 40 females) with an average age of 39.511 .0 years $(21 \sim 60$ years) (Seok et al., 2015). The study group reported that median nerve cross-sectional areas of the left and right wrists were $9.58 \pm 1.55 \mathrm{~mm}^{2}$ and $9.19 \pm$ $1.54 \mathrm{~mm}^{2}$, respectively. However, the results of these studies were too different from those of the present study and were even close to the normal upper limit of $9.79 \mathrm{~mm}^{2}$. Although these subjects were healthy without any neurological disease, the palm length was smaller in the 20 s and 30 s than in the male groups of the same age, This may be the reason why women are more sensitive to CTS.

In Table 2 of this study, it is interesting to note that the palm width (palm width) is narrower for the women in their 20 s and 30s than for men although these subjects are healthy without any neurological disease,

In both men and women in their 20 s and 30 s, the median nerve cross-sectional area and hand and wrist configurations were significantly higher in various parts of the arm as BMI was higher. These results are consistent with other studies. In this study, the higher the BMI, the higher the body weight and median nerve cross-sectional area, but the greater the palm horizontal size. Taser et al. (2017) recently described that shorter hand and square wrist configurations could predict the development of idiopathic carpal tunnel syndrome. Besides, they reported a $7.2 \pm 1 \mathrm{~mm}^{2}$ similar to our study in an investigation of median nerve cross-sectional areas of 100 healthy Asians. In conclusion, the median nerve crosssectional area and related variables were different according to gender, age, and body mass index, even though the participants in this study were healthy 20 s and 30 s young people without any neurological diseases or other diseases. Therefore, these variables should be considered when diagnosing or evaluating CTS for young ages.

The limitations of this study were that the subjects were not classified by occupation and did not investigate the computer and/or smartphone usage times of each individual.

Several studies have shown that repetitive computer tasks such as the use of computer mice and keyboards, computer work over one hour, and excessive use of smartphones put pressure on the median nerve and severely impaired the carpal tunnel, which is a risk factor for CTS (Thomsen et al., 2008; Gelfman et al., 2009; Toosi KK et al., 2011; Lee et al., 2012).

Therefore, further studies will be required by the age group, occupation, computer use, and smartphone use time. 


\section{ACKNOWLEDGEMENT}

None.

\section{CONFLICT OF INTEREST}

The authors declare that they have no conflict of interest.

\section{REFERENCES}

Burg EW, Bathala L, Visser LH. Difference in normal values of median nerve cross-sectional area between Dutch and Indian subjects. Muscle Nerve. 2014. 50: 129-132.

Bongers FJ, Schellevis FG, van den Bosch WJ. Carpal tunnel syndrome in general practice (1987 and 2001): incidence and the role of occupational and non-occupational factors. $\mathrm{Br} \mathrm{J}$ Gen Pract. 2007. 57: 36-39.

Gelfman R, Melton LJ 3rd, Yawn BP. Long-term trends in carpal tunnel syndrome. Neurology. 2009. 72: 33-41.

Katz AM, Messineo FC, Herbette L. Ion channels in membranes. Circlulation. 1982. 65: 2-10.

Kutlar N, Bayrak AO, Bayrak İK, Canbaz S, Türker H. Diagnosing carpal tunnel syndrome ith Doppler ultrasonography: a comparison of ultrasonographic measurements and electrophysiological severity. Neurol Res. 2017. 39: 126-132.

Lee YS, Yang HS, Jeong CJ, Yoo YD, Jeong GY, Moon JS, et al. Changes in the thickness of median nerves due to excessive use of smartphones. J Phys Ther Sci. 2012. 24: 1259-1262.

Palmer KT, Harris EC, Coggon D. Carpal tunnel syndrome and its relation to occupation: a systematic literature review. Occup
Med. 2007. 57: 57-66.

Rempel D, Evanoff B, Amadio PC. Consensus criteria for the classification of carpal tunnel syndrome in epidemiologic studies. Am J Public Health. 1998. 88: 1447-1451.

Seok JE, Lee SB, Bae CB. Ultrasonographic findings of the normal nerves in common entrapment site; Caross-sectional area reference value and normal variant. J Korean Neurol Assoc. 2015. 33: 8-12.

Stallings SP, Kasdan ML, Soergel TM, Corwin HM. A case-control study of obesity as a risk factor for carpal tunnel syndrome in a population of 600 patients presenting for independent medical examination. Journal of Hand Surgery. 1997. 22A: 211-215.

Taser F, Deger AN, Deger H. Comparative histopathological evaluation of patients with diabetes hypothyroidism and idiopathic carpal tunnel syndrome. Neurosurg. 2017. 27: 991 $-997$.

Toosi KK, Impink BG, Baker NA. Effects of computer keyboarding on ultrasonographic measures of the median nerve. Am J Ind Med. 2011. 54: 826-833.

Thomsen JF, Gerr F, Atroshi I. Carpal tunnel syndrome and the use of computer mouse and keyboard: a systematic review. BMC Musculoskelet Disord. 2008. 9: 134

https://doi.org/10.15616/BSL.2020.26.3.186

Cite this article as: Kang KH, Lee GH, Choi GE, Hyun KY. Mean Value of Median Nerve Cross-sectional Area in Healthy 20s and 30s in Busan Area. Biomedical Science Letters. 2020. 26: 186-191. 